American Journal of Agricultural and Biological Sciences 4 (1): 1-6, 2009

ISSN 1557-4989

(C) 2009 Science Publications

\title{
Does Trichomes on the Plant Epidermic Surface Disturb Ants Locomotion?
}

\author{
${ }^{1}$ Danon Clemes Cardoso, ${ }^{2}$ Maykon Passos Cristiano, ${ }^{3}$ Lenise Cristina Moraes Vilela \\ and ${ }^{3}$ Tiago de Arruda Martins \\ ${ }^{1}$ Deparment of Animal Biology, Graduate Program in Entomology \\ Federal University of Viçosa-UFV \\ ${ }^{2}$ Department of General Biology, Graduate Program in Genetics and \\ Improvement, Federal University of Viçosa-UFV \\ ${ }^{3}$ Department of Fitotecny, Undergraduate in Agronomy, Federal University of Viçosa-UFV
}

\begin{abstract}
Problem Statement: Many morphological characteristics, both physical and chemical, are used in the defense against herbivores on plants. Trichomes are structures used by plants as physics defense and when associated with glands combine physics and chemistry defense. Many species of ants are herbivores and use leaves and seeds, others ants use Extra Floral Nectars as a food resource, and the majority of the species are predators of other ants and other insects, and use plants as foraging substrate in search of prey. Likewise, on the assumption that ants feed preferentially in plants free of trichomes, we tested the hypothesis that trichomes plants clouded locomotion of ants. Approach: Experiments were carried out in the field using cotton to mimic the plants surface. Thirty traps for the treatment were assembled with cotton as well as other 30 experiments for the control (treatment without cotton). Each trap consisted of Petri dishes of 14,5 cm diameter with bait (sardine and honey) in a disc $(3 \mathrm{~cm}$ diameter) in the center of the plate. Around the bait, 10 grams of cotton prepared uniformly were placed. Furthermore, morphometric analysis on the length of body and legs of ants was performed. Results: The number of ants which accessed baits in the center of Petri dishes in treatment with cotton was not statistically different of the number of accesses in the control treatment without cotton. The trichomes do not cloud locomotion of ants and that leg length is equal to or greater than body length. Conclusions/Recommendations: Data revealed that the trichomes do not cloud locomotion of ants; this allows the free walking of ants on the plants surface. However, glandular trichomes that combine physics and chemistry defense with release toxic and adhesives compounds when mechanically stressed may be more efficient in the defense against these insects.
\end{abstract}

Key words: Trichomes, formicidae, insect-plant interaction, plant defense, morphometric

\section{INTRODUCTION}

Throughout its history plants have developed different evolutionary techniques for protection against most of several predators, in particular insects. These animals are the most abundant in kind than any other class of organism and more than 400.000 species of insects are herbivores ${ }^{[1]}$. Various characteristics such as morphological, physics and chemical interfere directly or indirectly on insects, producing adverse effects on their behavior and biology ${ }^{[2]}$. Among the chemical defense mechanisms against herbivores we may highlight toxic compounds of secondary metabolites of plants which can act as repellents or even affect the physiology of herbivore insects. As to physical mechanisms cellular wall thickness, thorns and trichomes may be highlighted ${ }^{[3]}$. Trichomes are structures of the epidermis of the plant which may be simple, formed by only one cell, or, multicelular ${ }^{[4]}$. Collectively, the trichomes are the pilosity of the plants surface $^{[1]}$ and are defined according to Steinite and Ievinsh $^{[4]}$, as specialized structures in the defense against insects and mites. The trichomes can affect species of insects in four ways: (i) affecting oviposition of the insect, (ii) rate of locomotion on surface, (iii) inhibiting feeding and growth for nutritional quality and (iv) increase exposure to predation ${ }^{[5]}$.

For plants, the crucial advantage of insect-plant interaction is the pollination, in this context, plants have mechanisms to protect against ants, since these insects

Corresponding Author: Danon Clemes Cardoso, Graduate Program in Entomology-Department of Animal Biology-Federal University of Viçosa-UFV. Av P.H. Rolfs, s/n, 36570-000, Viçosa, Minas Gerais, Brazil. Phone: $+55313899-4018$ 
are poor pollinators and also voracious nectar devour. One mechanism that plants use for the protection against ants is the production of latex. This is occurs in many species of the family Moracea ${ }^{[6]}$.

However, many plants established strong mutual relations with insects, even specific close relations. Many authors highlight that several plants provide food resources through Extra Floral Nectaries (EFNs) for ants in exchange for protection from predators. Ants protect the area of foraging, in plants that ants were present there was less herbivore than in plants where ants were absent ${ }^{[7,8]}$. Ants are intense foragers in many plant species in the Neotropical regions and dominate the canopy forest. Many species of ants are herbivores and use leaves and seeds, as the case of "leaf cutting ants" of the genus Atta and Acromyrmex, to supply their symbiotic fungus. Others ants use EFNs as a food resource, and the majority of the species are predators of other ants and other insects, and use plants as foraging substrate in search of prey ${ }^{[9]}$.

Considering the importance of the plants as foraging substrate for ants we attempted to verify whether trichomes of the plants surface disturb the locomotion of ants, assuming that ants forage especially in plants free of trichomes. Thus, the aim in this work is to test whether the plants surface hinder the locomotion of the ants through new techniques of mimicry of these structures. Moreover, we also demonstrate that simple techniques are so value tools in biological studies and contribute to basic science. Furthermore, a morphometric analysis on the length of body and legs of ants was performed to verify the following assumptions: (i) the length of legs of the ants is equal to or greater than the body length, and (ii) the length measures of the body are directly proportional to the length of legs.

\section{MATERIALS AND METHODS}

Locomotion tests: For testing the hypothesis that trichomes cloud locomotion of ants, experiments using cotton to mimic the texture of the pilose plant surface were carried out in the field. Thirty traps for the treatment were assembled with cotton as well as other 30 experiments for the control (treatment without cotton). Each trap consisted of petri dishes of $14,5 \mathrm{~cm}$ diameter with bait (sardine and honey) in a disc $(3 \mathrm{~cm}$ diameter) in the center of the plate. Around the bait, 10 grams of cotton prepared uniformly were placed, for the treatment with cotton, or, without cotton for the control treatment. The number of ants which accessed the bait was summarized and two models were compared. The fitted models composed the numbers of species that

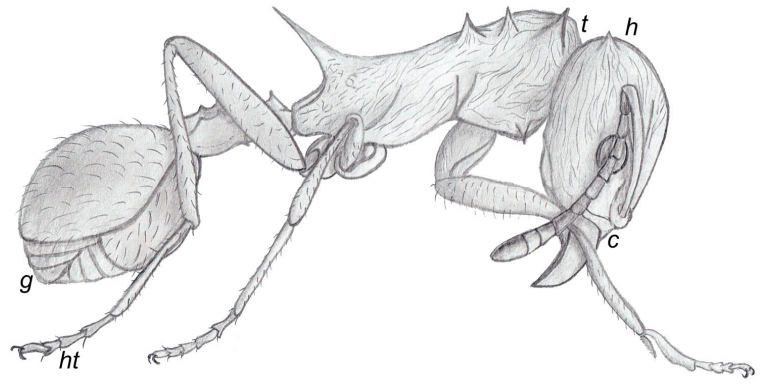

Fig.1: Morphological features measured of the ants. Body length: extent of the head (to clypeus "c" from head apex "a") summed an extent of to gaster "g" from alitrunk (= mesosoma) " $t$ " and the Leg length: extent of the tarsi, tibia and femur of the hind leg "hl". Schematic drawing of Acromyrmex striatus.

accessed the bait for two treatments and compared with the fixed model (or null model), without interaction, through analysis of variance (ANOVA) using Poisson errors adjusted due over dispersion. The two models were investigated as required using Chi-squared test.

Morphometric analyses: The morphometry was performed in microscope stereoscopy LEICA® MZ12 in eyepiece of 10x endowed with reticulum with scale. Thirty ants were analyzed, five of each genus: Camponotus, Ectatomma, Atta, Crematogaster, Pheidole, Dorymyrmex. Were measured the length of the hind leg and body (Fig. 1). The relationships between the length of body and leg length were examined with Pearson correlation analyses.

Statistical analyses: All analyses were performed using the statistical program $\mathrm{R}^{[10]}$ which were followed by residual analyses to verify the suitability of models and distribution of errors ${ }^{[11]}$. All experiments were carried out in the areas around the Biological Reserve of the Biology of Federal University of Viçosa (Federal University of Viçosa-UFV) in Minas Gerais state, Brazil.

\section{RESULTS}

The number of ants which accessed baits in the center of petri dishes in treatment with cotton was not statistically different of the number of accesses in the control treatment without cotton $\left(\chi^{2}=0.05 ; \mathrm{p}=0.95\right)$ (Fig. 2). The null hypothesis that trichomes do not cloud locomotion of ants was accepted. 


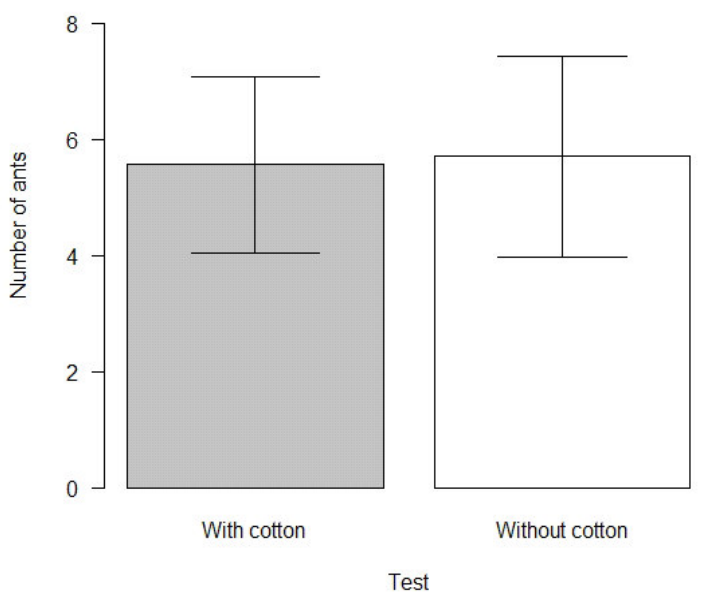

Fig. 2: Number the ants that accessed the bait in the center of petri dishes in the field tests for treatments with and without cotton. The treatments were not different statistically (ANOVA: $\chi^{2}=0.05 ; \mathrm{p}=0.95 ; d f=58$ )

Table 1: Measures of the leg and body length (mean \pm SEM) of ants

\begin{tabular}{lcc}
\hline Taxa & Body length & Leg length \\
\hline $\begin{array}{l}\text { Formicinae } \\
\text { Camponotus }\end{array}$ & $10.62 \pm 0.12$ & $13.274 \pm 0.32$ \\
$\begin{array}{l}\text { Ectatomminae } \\
\text { Myrmicinae }\end{array}$ & $9.72 \pm 0.34$ & $9.95 \pm 0.20$ \\
Atta & & \\
Pheidole & $6.525 \pm 0.35$ & $11.35 \pm 0.35$ \\
Crematogaster & $2.63 \pm 0.13$ & $3.149 \pm 0.19$ \\
Dolichoderinae & $2.85 \pm 0.38$ & $1.47 \pm 0.12$ \\
Dorymyrmex & & \\
\hline & $3.05 \pm 0.11$ & $4.05 \pm 0.23$ \\
\hline
\end{tabular}

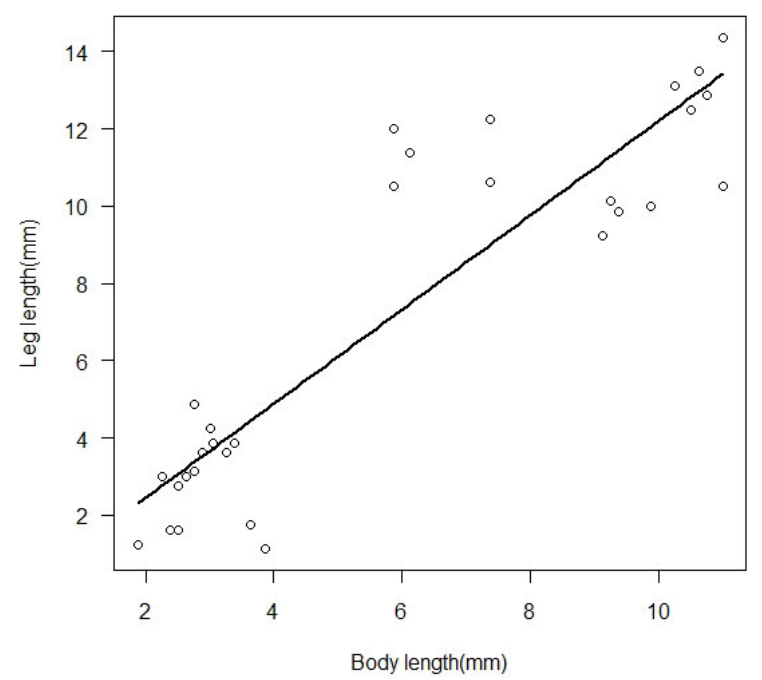

Fig. 3: Pearson correlation analyses, the leg length increases the greater will body length be $(\mathrm{r}=0.9031795, d f=28, \mathrm{p}=0.001)$
In Table 1, measures of body length and leg of the ants are shown. With the exception of the genus Crematogaster, all the others genera possess the length of the leg greater than the length of the body. Meanwhile, the leg length of genus Crematogaster is larger than half of the body length. The Fig. 3 showed the Person's correlation analyzes amongst leg and body length. These correlation was highly significant $(\mathrm{r}=$ $0.9031795, d f=28, \mathrm{p}=0.001)$. There was a positive correlation amongst of leg length and body.

\section{DISCUSSION}

Given that the number of accesses to bait was not different among treatments, it is supposed that ants do not have any difficulty of locomotion on pilose areas, therefore simple trichomes, those without glandular structures ancillary, are not effective physical barriers against ants. For many ants, the plants are not food sources by direct relationship of vegetal material consumption. The exception, are the leaf cutting ants, which consume large quantities of vegetal material for the cultivation of symbiotic fungus ${ }^{12,}$ 13, 14]. Many others ants use plants through the consumption of nectar released in extrafloral nectaries (ENfs), but also as foraging area for predation of other insects, like others ants. Thus, the trichomes may be not affect them directly, whereas they are efficient physical barriers as high densities against herbivores consumers of leaves ${ }^{[4]}$. Trichomes have been widely exploited as an insect defense mechanism in a number of crop plants that include Phaseolus ${ }^{[15]}$, potato ${ }^{[16]}$, soybean ${ }^{[17]}$ and tomato $^{[18,19,20]}$. Moreover, the ants exhibiting long legs, longer than body length (Fig. 3 and Table 1), may move without difficulties on plants surface that show these structures probably because exceeded height of trichomes. Regarding results, the mired bug Dicyphus errans (Heteroptera) live and prey others arthropods on plants with pilose surface more efficiently because species of the pubescent plants grants a more appropriated microenvironment. The trichomes enable a stronger attachment for this is insects and more autonomic walking on the leaf ${ }^{[21]}$.

In contrast, larval stages the many insects, in particular caterpillars, have great difficulty to move on surface with trichomes. Fordyce and Agrawal ${ }^{[22]}$, performing experiments with the caterpillar Chrysopa cárnea observed that, in order of a predator, the rate of caterpillar leakage decreased as the density of trichomes increased, certainly due its anatomy and morphology. Furthermore, the larvae submitted preferably to foraging areas with lower density of trichomes, for example, young leaves. Likewise, the 
trichomes showed to be effective against nymphs of Podisus maculiventris (Pentadomidae), whereas the non-glandular trichomes were efficient agents leading to death of nymphs in up to four days ${ }^{[23]}$. This is corroborated with Segatto ${ }^{[24]}$, which considered plants with higher density of trichomes more resistant against insects attacks comparing to plants considered susceptible to herbivores.

Ants are eusocial insects, with organisms presenting overlapping of generations, parental care and division the caste ${ }^{[25]}$. Most ants have two morphologically distinctive female castes: the queen, which is responsible for egg laying, and the workers, that perform almost all other tasks required for the maintenance and survival of the colony ${ }^{[26,27]}$. Some workers provide care and food to larvae into the nest and just the adult workers are responsible for foraging outside the colony. Our observations from morphometric dates show that foragers ants have leg length same size as body length. We believe that this proportion is necessary because in case of defense or attack the ants bend their abdomen (or gaster) under the body with the aim of achieve her attacker or prey $^{[12,28,29,30]}$. However, in Crematogaster, the length body was larger than leg length. Also, this happens because the genus Crematogaster is the only genus amongst the ants which is able to bend the abdomen into the body ${ }^{[12]}$. Nevertheless, the leg length longer than half the body length may overcome the height of trichomes as the other ants.

In experiments with several orders of insects, Gladun and Gorb ${ }^{[31]}$ demonstrated that they have used a variety of structures, such as arolium, claws and spur, to fix on smooth and cylindrical surfaces, showing that organisms have developed many abilities of locomotion on different surfaces. Moreover, the Hymenoptera species demonstrated capability of strong bending and overextension of tarsus despite the need and depending on surface that insect is on. Thus, ants probably overextend theirs legs associated to an overextension of tarsus to escape the defensive action of non-glandular trichomes. However our experiments do not allow conclusion on the defensive action of the glandular trichomes. The glandular trichomes many times were discovered together with non-glandular trichomes in the same plant, for example, tomatoes exhibit at least three defenses against insects: allelochemical, glandular trichomes and non-glandular trichomes ${ }^{[23]}$. The glandular trichomes release many exudates as a large variety of terpene oils and many other essential oils ${ }^{[1]}$. These may operate as repellent, deterrents and toxic or glue the tarsus and legs of the many arthropods, when later the organism will succumb for immobilization and/or die of starvation ${ }^{[23]}$.

\section{CONCLUSION}

It is concluded that simple trichomes do not cloud locomotion of ants, thus plants with simple trichomes do not present resistance to attack from these insects. In the meantime, glandular trichomes that combine physics and chemistry defense release adhesives and toxics compounds when mechanically stressed may be efficient in the defense against insects.

\section{ACKNOWLEDGMENT}

We thank the J.H. Schoereder for helpful discussion and comments on this statistical analyses and M.S. Raymundo for comments on this manuscript. This research was partially produced during the Population Ecology classes and was supported by the Brazilian research agencies CAPES and CNPq.

\section{REFERENCES}

1. Schoonhoven, L.M., J.J.A. Van Loon and M. Dicke, 2006. Insect Plant Biology. 2nd Edn. Oxford University Press. UK. pp: 440. ISBN13: 9780198525950

2. Chehab, E.W., R. Kaspi, T. Savchenko, H. Rowe, F. Negre-Zakharov, D. Kliebenstein and $\mathrm{K}$. Dehesh, 2008. Distinct roles of jasmonates and aldehydes in plant-defense responses. PLoSONE, 3: 1904. DOI: 10.1371/journal.pone.0001904.

3. Núñez-Farfán, J., J. Fornoni \& P.L. Valverde 2007. The evolution of resistance and tolerance to herbivores. Ann. Rev. Ecolo. Evolution Systematics, 38: 541-566.

DOI: 10.1146/annurev.ecolsys.38.091206.095822

4. Steinite, I. and G. Ievinsh, 2003. Possible role of trichomes in resistance of strawberry cultivars against spider mite. Acta Universitatis Latviensis, 662: 59-65.

http://priede.bf.lu.lv/grozs/LU/LU_Bio_Raksti/LU BioRaksti/2003/Steinite.pdf

5. Andres, M.R. and E.F. Connor 2003. The community-wide and guild-specific effects of pubescence on the folivorous insects of manzanitas Arctostaphylos spp. Ecol. Entomol. 28: 383-396. DOI: 10.1046/j.1365-2311.2003.00532.x

6. Delabie, J.H.C., M. Ospina and G. Zabala, 2003. Hormiga and relationships between plants: an introduction. In: Introduction to ants in the Neotropical region. Research Institute of Biological Resources Alexander Von Humboldt, Bogotá, Colombia, Fernandez F. (Ed.). pp: 97-112. http://antbase.org/ants/publications/20981/20981.pdf 
7. Oliveira, P.S. and M.R. Pie 1998. Interaction between ants and plants bearing extrafloral nectaries in cerrado vegetation. Ann. Entomol. Soc. Brazil, 27: 161-176. http://www.scielo.br/pdf/aseb/v27n2/v27n2a01.pdf

8. Korndörfer, A.P. and K. Del-Claro 2006. Ant defense versus induced defense in Lafoensia pacari (lythraceae), a myrmecophilous tree of the brazilian Cerrado. Biotropica, 38: 786-788. DOI: 10.1111/j.1744-7429.2006.00200.x

9. Peternelli, E.F.O., T.M.C. Della-Lucia and S.V. Martins 2004. Espécies de formigas que interagem com as sementes de Mabea fistulifera Mart. (Euphorbiaceae). Revista Árvore 28:733-738. DOI: 10.1590/S0100-67622004000500013

10. R Development Core Team 2008. R: A Language and Environment for Statistical Computing. R Foundation for Statistical Computing, Vienna, Austria. ISBN: 3-900051-07-0.

11. Crawley, M.J., 2002 Statistical Computing-An introduction to data analysis using S-plus. John Wiley and Sons, England. pp: 772. ISBN: 978-0471-56040-1.

12. Hölldobler, B. and E.O. Wilson 1990. The Ants. Springer-Verlag, Berlin, Heidelberg, 1st Edn., pp: 10-55. ISBN: 978-3-540-52092-4.

13. Hertz, H., W. Beyschlag and B. Hölldobler, 2007. Assessing herbivory rates of leaf-cutting ant (Atta colombica) colonies through short-term refuse deposition counts. Biotropica, 39: 476-481. DOI: 10.1111/j.1744-7429.2007.00283.x

14. Cardoso, D.C., J.C. Fortes, M.P. Cristiano, J.C. Zanunico and J.E. Serrão 2008. Spermathecae and Associated Glands of the Ants Solenopsis saevissima and Acromyrmex subterraneus subterraneus (Hymenoptera: Myrmicinae) Sociobiology 52: 377-385. http://www.csuchico.edu/biol/Sociobiology/sociobi ologycurrent.html\#12

15. Oku, K., S. Yano and A. Takafuji, 2006. Host plant acceptance by the phytophagous mite Tetranychus kanzawai Kishida is affected by the availability of a refuge on the leaf surface. Ecol. Res., 21: 446452. DOI: 10.1007/s11284-005-0141-y

16. Yencho, G.C. and W.M. Tingey, 1994. Glandular trichomes of Solanum berthaultii alter host preference of the Colorado potato Beetle, Leptinotarsa decemlineata. Entomol. Experimentalis Appli., 70: 217-225. DOI: 10.1007/BF02380555.
17. Lee, Y.I., M. Kogan and J.R. Larsen, 1986. Attachment of the potato leafhopper to soybean plant surfaces as affected by morphology of the pretarsus. Entomol. Experimentalis Appli., 42:101107. DOI: $10.1007 / \mathrm{BF} 00343535$

18. Wilkens, R.T., G.O. Shea, S. Halbreich and N.E. Stamp, 1996. Resource availability and the trichome defenses of tomato plants. Oecologia 106:181-191. DOI: 10.1007/BF00328597

19. Heinz, K.M. and F.G. Zalom 1997. Performance of the predator Delphastus pusillus on Bemisia resistant and susceptible tomato lines. Entomol. Experimentalis Appli., 81: 345-352. DOI: 10.1046/j.1570-7458.1996.00105.x

20. Simmons, A.T. and G.M. Gurr, 2004. Trichomebased host plant resistance of Lycopersicon species and the biocontrol agent Mallada signata: are they compatible? Entomologia Experimentalis et Applicata 113:95-101. DOI: 10.1111/j.00138703.2004.00210.x

21. Voigt, D., E. Gorb and S. Gorb, 2007. Plant surface-bug interactions: Dicyphus errans stalking along trichomes. Arthropod-Plant Interact 1: 221243. DOI: $10.1007 / \mathrm{s} 11829-007-9021-4$

22. Fordyce, J.A. \& A.A. Agrawal 2001. The role of plant trichomes and caterpillar group size on growth and defense of the pipevine swallowtail Battus philenor. J. Animal Ecol., 70: 997-1005. DOI: 10.1046/j.0021-8790.2001.00568.x

23. Lambert, A.M. 2007. Effects of pry availability, facultative plant feeding, and plant defenses on a generalist insect predator. Arthropod-Plant Interact 1: 167-173. DOI: $10.1007 / \mathrm{s} 11829-007-9015-2$

24. Segatto, F.B., D.A. Bisognin, M. Benedetti, L.C. Costa, M.V. Rampelotto and F.T. Nicoloso, 2004. Techniques to study the anatomy of the leaf epidermis of potato. Rural Sci., 34:1597-1601. DOI: $10.1590 / \mathrm{S} 0103-84782004000500042$

25. Wilson, E.O., 2008. One giant leap: how insects achieved altruism and colonial life. Bioscience, 58:17-25. DOI: 10.1641/B580106

26. Heinze, J., S. Foitzik, B. Oberstadt, O. Rüppell and B. Hölldobler, 1999. A female caste specialized for the production of unfertilized eggs in the ant Crematogaster smithi. Naturwissenschaften 86: 9395. DOI: $10.1007 / \mathrm{s} 001140050579$

27. Dietemann, V., C. Peeters and B. Hölldobler 2004. Gamergates in the Australian ant subfamily Myrmeciinae. Naturwissenschaften 91:432-435. DOI: $10.1007 /$ s00114-004-0549-1 
28. Mercier, J.L., A. Lenoir and A. Dejean, 1997. Ritualised versus aggressive behaviors displayed by Polyrhachis laboriosa (F. Smith) during intraspecific competition. Behavioural Proc., 41: 39-50. DOI: 10.1007/BF01253952

29. Dietemann, V., B. Hölldobler and C. Peeters, 2002. Caste specialization and differentiation in reproductive potential in the phylogenetically primitive ant Myrmecia gulosa. Insectes Sociaux, 49: 289-298. DOI: 10.1007/s00040-002-8316-9.
30. Kenne, M., R. Mony, M. Tindo, L.C.K. Njaleu, J. Orivel and A. Dejean, 2005. The predatory behavior of a tramp ant species in its native range. Comptes Redus Biol., 328: 1025-1030. DOI:10.1016/j.crvi.2005.09.001.

31. Gladun, D. and S.N. Gorb, 2007. Insect walking techniques on thin stems. Arthropod-Plant Interact, 01: 77-91. DOI: 10.1007/s11829-007-9007-2. 